\title{
Ventilatory function after exposure to various respirable hazards in a population of former coal miners
}

\author{
Geoffrey M Calvert, Maureen Moore, Stephen M Hessl
}

\begin{abstract}
The ventilatory function of $\mathbf{4 0 6}$ male former coal miners who had presented at the Cook County Hospital occupational medicine clinic between January 1976 and April 1987 was studied to determine whether subsequent exposure to respiratory hazards after leaving the coal mines adversely affected lung function. The miners were divided into five exposure groups based on their exposure to respirable hazards. These were coal dust only, coal dust plus asbestos dust, coal dust plus silica dust, coal dust plus another respirable hazard and coal dust plus two other respirable dust exposures. Duration of employment in coal mines, race, smoking history, and mean age were not significantly different between the various exposure groups. No significant difference was found in the per cent of predicted forced expiratory volume in one second $\left(F E V_{1}\right)$, per cent of predicted forced vital capacity (FVC), and $F E V_{1} / F V C$ when the coal dust only group was compared with each of the other four exposure groups using ANOVA. Among former coal miners who present for a respiratory disability determination, therefore, exposure to respirable hazards subsequent to employment in coal mines is not associated with a statistically significant deterioration in ventilatory function.
\end{abstract}

Testing of pulmonary function has an important role in the evaluation of lung disease in coal miners. Although such testing is not useful for diagnosing coal workers' pneumoconiosis, ${ }^{1}$ it is useful for evaluating chronic respiratory impairment and as such it is employed under the United States Black Lung Benefit Act to determine eligibility for benefits. $^{2}$

Division of Occupational Medicine, Cook County Hospital, Chicago, Illinois, USA

G M Calvert, $M$ Moore, S M Hessl
After leaving the coal mines, miners often have a history of employment in jobs where they are exposed to respiratory hazards; the effect of subsequent exposure on ventilatory function and, in turn, on eligibility benefit has never been studied in ex-coal miners. Although there are a few reports on the ventilatory function of coal miners who left the industry to take other jobs, ${ }^{3-5}$ none of them evaluated the effects of exposure to respiratory hazards that may have been present in those other jobs.

The aim of our study was to determine if occupational exposure to respiratory hazards subsequent to employment in coal mines was associated with a statistically significant decline in ventilatory function. We studied former coal miners who migrated to the Chicago area where they frequently obtained employment in the steel industry, in industries utilising asbestos, and in other workplaces in which exposure to fibrogenic dusts, fibres, and fumes were common.

\section{Methods}

The charts of former coal miners who presented to the occupational medicine clinic of the Cook County Hospital for evaluations of disability to obtain benefits under the United States Department of Labor Black Lung Benefit Act were reviewed. Because this is the only clinic in the Chicago area that receives federal funding to perform assessments for benefit because of black lung disability it primarily serves former coal miners of low or modest financial means. All former coal miners who were assessed between January 1976 and April 1987 were considered for inclusion in the study.

To qualify, a miner's chart had to contain a complete occupational history, information on smoking, and information on race and tests of pulmonary function that met the American Thoracic Society (ATS) standards. ${ }^{6}$ The charts of 406 former coal miners met all the criteria and were included in the study. One hundred and fifty eight miners were excluded because their tests did not meet the ATS standards.

The information collected included age, duration of employment in coal mines, duration of exposure to 
asbestos, silica, and other respiratory hazards (such as welding fumes, isocyanates, and cotton dust), and history of smoking. Data on cumulative dust exposure were not in the charts and were not collected. Pack-years of smoking were calculated by multiplying the average number of packs of cigarettes smoked each day by the number of years during which the miner had smoked.

The participants were divided into five groups based on exposure: group 1, exposure to coal dust only; group 2, exposure to coal dust and asbestos dust; group 3, exposure to coal dust and silica dust; group 4, exposure to coal dust and a miscellaneous respiratory hazard (welding fumes, plastic fumes, or cotton dust); and group 5, exposure to coal dust and two or more respiratory hazards.

Most tests of pulmonary function were obtained with the $47120 \mathrm{~A}$ Hewlett Packard System ${ }^{\mathrm{R}}$. The remainder were performed on the SLR series 5000 pulmolab ${ }^{\mathrm{R}}$. Tests of pulmonary function for all coal miners enrolled in the study were corrected to body temperature, pressure, and saturation. Per cent of predicted values for forced expiratory volume in one second $\left(\mathrm{FEV}_{1}\right)$ and forced vital capacity $(\mathrm{FVC})$ was calculated as previously described. ${ }^{7}$ To correct for the known racial difference in parameters of pulmonary function the expected $\mathrm{FEV}_{1}$ and FVC for black subjects were multiplied by $0 \cdot 85 .^{8}$

Mantel-Haenszel $\chi^{2}$ tests were performed to determine if the exposure groups were similar in proportions of race and smoking state (former, current, or non-smoker). ${ }^{9}$ Analysis of variance (ANOVA) was carried out to determine if significant differences between the different exposure groups existed for measures of ventilatory function, pack-years, height, duration of exposure to coal dust, duration of exposure to non-coal dust hazards, and age. ${ }^{9}$ The $\mathrm{FEV}_{1}, \mathrm{FVC}$, and the $\mathrm{FEV}_{1} / \mathrm{FVC}$ were regressed against the independent variables of exposure group, height, age, race, duration of exposure to respirable hazards excluding coal dust, smoking state, and pack-years smoked. ${ }^{9}$ To assess participant effort on pulmonary function testing, an aggregate maximum voluntary ventilation $(\mathrm{MVV}) / \mathrm{FEV}_{1}$ ratio was calcu- lated for each respiratory technician. ${ }^{10}$ The combined mean for all respiratory technicians was $33 \cdot 2$.

\section{Results}

All five exposure groups were similar for race, mean age, mean height, smoking state, mean number of pack-years smoked, and mean duration of exposure to coal dust (table). The mean duration of exposure to respirable hazards excluding exposure to coal dust was determined for each group. Statistically significant differences in this measure were found for each exposure group when compared with each of the other groups using non-paired $t$ tests, except that no difference was found between group 2 and group 5 (table).

No statistically significant differences in ventilatory function were found between the exposure groups with ANOVA (table) or with linear regression analysis to control for important factors of lung function risk. Inclusion of the 158 miners in the analysis who did not qualify for the study because variability of spirometry exceeded the ATS guidelines, or of data from non-smokers only did not produce any significant differences either.

\section{Discussion}

Our study found that among former coal miners claiming disability, occupational exposure to respiratory hazards subsequent to employment in coal mines was not associated with a significant deterioration in ventilatory function when compared with former coal miners having no occupational exposure to respirable hazards after leaving the mines. We are aware of no other study that compared ventilatory function between former coal miners with and without occupational exposure to respirable hazards after employment in coal mines.

This cohort has been studied previously when it was found that chest $x$ ray photographs from groups $2,3,4$, and 5 were more likely to have small opacities consistent with pneumoconiosis than those of group 1. Only $14 \cdot 6^{\circ}{ }_{0}$ with exposure only to coal dust and

Demographic characteristics and ventilatory function by exposure group

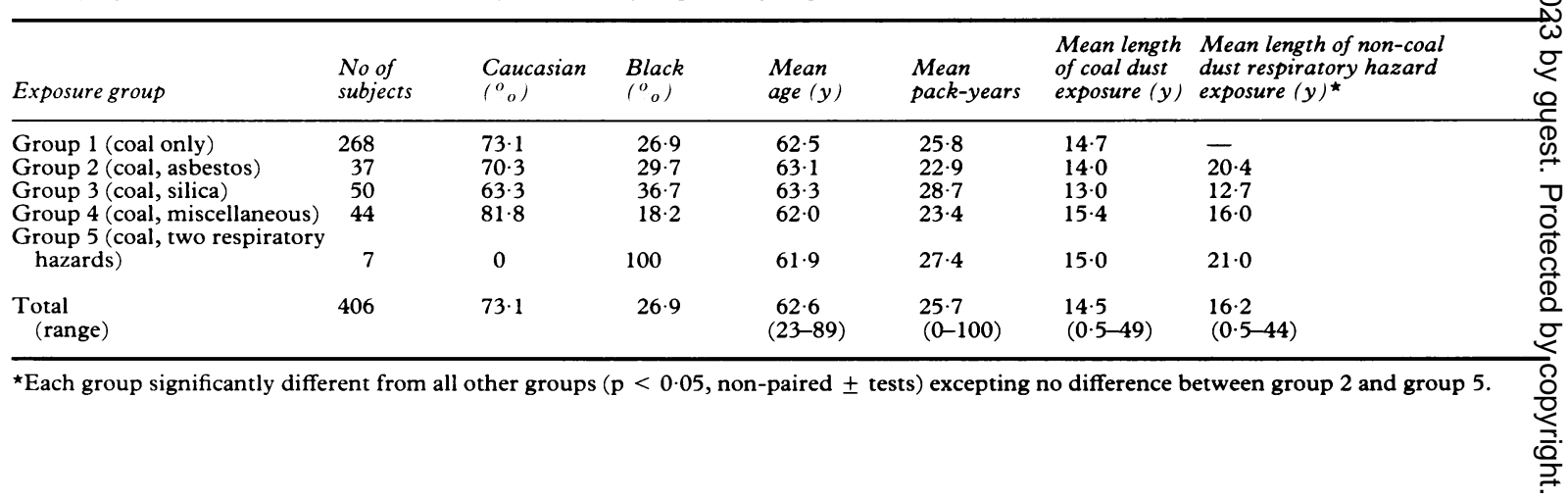


$37 \%$ with exposure to coal dust and another respirable hazard, however, had a profusion of opacities on chest $x$ ray film greater than or equal to $1 / 1 .^{11}$

Thus most of the sample had little or no radiographic evidence of pneumoconiosis, which helps to explain our findings. In coal workers' pneumoconiosis, impairment of ventilatory function is not seen until the disease is advanced, and associated with large opacities of high profusion on radiography. ${ }^{12}$ Likewise, impairment of ventilatory function is generally absent in the early radiographic stages of silicosis. ${ }^{13}$

In workers exposed to asbestos, pulmonary function appears to be better correlated with cumulative exposure to dust than with extent of radiographic change. ${ }^{14}$ Our failure to find a significant difference in ventilatory function in the asbestos exposed group (group 2) may indicate that exposure to asbestos was not high enough to adversely affect pulmonary function. We cannot confirm this since data on cumulative dust exposure were not available.

The limitations of our study may, at least in part, be responsible for our findings. Our sample consisted only of ex-coal miners who received a disability determination for black lung benefit at the Cook County Hospital Occupational Medicine Clinic; it is a non-randomised, self selected population and is prone to selection bias. We were unable to determine the effect of selection factors such as survival, socioeconomic state (the clinic primarily serves those of low or modest financial means), or exclusion of workers not sick enough to seek a disability determination. Also, we did not use a control group. Instead, our findings were based on comparisons of mean ventilatory function between the five exposure groups.

The effect of subsequent exposure to respiratory hazards on ventilatory function has never been studied in ex-coal miners. Although Hurley and Soutar ${ }^{34}$ examined the ventilatory function in ex-coal miners with chronic bronchitis who left the coal mines for other employment, they did not report if the other employment was associated with exposure to respiratory hazards. Lowe and $\mathrm{Khosla}^{5}$ compared the $\mathrm{FEV}_{1} / \mathrm{FVC}$ ratio between two groups of steel-

\begin{tabular}{|c|c|c|c|c|}
\hline $\begin{array}{l}\text { Mean } \\
F E V_{1}(l)\end{array}$ & $\begin{array}{l}\text { Mean } \\
F E V_{1} \dagger(\%)\end{array}$ & $\begin{array}{l}\text { Mean } \\
F V C(l)\end{array}$ & $\begin{array}{l}\text { Mean } \\
F V C \dagger(\%)\end{array}$ & $\begin{array}{l}\text { Mean } \\
F E V_{1} / F V C \\
(\%)\end{array}$ \\
\hline $\begin{array}{l}2.41 \\
2.39 \\
2.42 \\
2.57 \\
2.54\end{array}$ & $\begin{array}{l}71 \cdot 5 \\
74 \cdot 3 \\
72 \cdot 7 \\
73 \cdot 2 \\
70 \cdot 7\end{array}$ & $\begin{array}{l}3 \cdot 61 \\
3 \cdot 46 \\
3 \cdot 63 \\
3 \cdot 71 \\
4 \cdot 26\end{array}$ & $\begin{array}{l}84 \cdot 3 \\
83 \cdot 4 \\
85 \cdot 4 \\
83 \cdot 4 \\
91 \cdot 7\end{array}$ & $\begin{array}{l}66 \cdot 6 \\
68 \cdot 3 \\
67 \cdot 8 \\
68 \cdot 2 \\
60 \cdot 2\end{array}$ \\
\hline $2 \cdot 43$ & $72 \cdot 1$ & 3.63 & $84 \cdot 4$ & 66.9 \\
\hline
\end{tabular}

+Per cent of predicted value using formulas from Crapo $\mathrm{et} \mathrm{al.}{ }^{7}$ workers. One group were ex-coal miners and the other had no history of employment in coal mines. These investigators studied the impact of previous employment in coal mines on ventilatory function in steelworkers. The effect of steelwork on ventilatory function in ex-coal miners was not considered.

In conclusion, our findings indicate that among former coal miners who present for a determination of disability due to black lung, exposure to occupational respiratory hazards subsequent to employment in coal mines is not associated with a statistically significant decline in ventilatory function. Because of the recognised limitations of our study, however, further investigation is warranted.

We thank Daniel O Hryhorczuk MD, MPH, for his valuable suggestions and James A Morris, MS, for his help with the statistical analysis.

Requests for reprints to: Stephen M Hessl, MD, MPH, Division of Occupational Medicine, Cook County Hospital, 720 South Wolcott Street, Chicago, IL 60612, USA.

1 Parkes WR. Occupational lung diseases. 2nd ed. London: Butterworths, 1982:195-7.

2 Department of Labor. Standards for determining coal miners' total disability or death due to pneumoconiosis. Federal Register 1980;45:13678-712.

3 Hurley JF, Soutar CA. Can exposure to coalmine dust cause a severe impairment of lung function? $\mathrm{Br} J$ Ind Med 1986; 43:150-7.

4 Soutar CA, Hurley JF. Relation between dust exposure and lung function in miners and ex-miners. $B r J$ Ind Med 1986;43: 307-20.

5 Lowe CR, Khosla T. Chronic bronchitis in ex-coal miners working in the steel industry. Br J Ind Med 1972;29:45-9.

6 American Thoracic Society. ATS statement. Snowbird workshop on standardisation of spirometry. Am Rev Respir Dis 1979;119:831-8.

7 Crapo RO, Morris AH, Gardner RM. Reference spirometric values using techniques and equipment that meet ATS recommendations. Am Rev Respir Dis 1981;123:659-64.

$8 \mathrm{NIOSH}$. Manual of Spirometry in Occupational Medicine. Division of Training and Manpower Development, Cincinnati, US Department of Health and Human Services, Public Health Service, Center for Disease Control, National Institute for Occupational Safety and Health, 1981.

9 SAS Users Guide: Statistics. 5th ed. Cary NC: SAS Institute, 1985.

10 Harber P, SooHoo K, Tashkin DP. Is the MVV:FEV ratio useful for assessing spirometry validity? Chest 1985;88:52-7.

11 King MA, Hessl SM. The effect of occupational exposures in a population of former coal workers. Annals of the American Conference of Governmental Industrial Hygienists 1986;14: 101-5.

12 Cochrane AL, Higgins ITT. Pulmonary ventilatory functions of coal miners in various areas in relation to the $\mathrm{x}$-ray category of pneumoconiosis. British Journal of Preventive and Social Medicine 1961;15:1-11.

13 Irwing LM, Rocks P. Lung function and respiratory symptoms in silicotic and nonsilicotic gold mines. Am Rev Respir Dis 1978;117:429-35.

14 Weill H, Ziskind MM, Waggenspack C, Rossiter CE. Lung function consequences of dust exposure in asbestos cement manufacturing plants. Arch Environ Health 1975;30:88-97.

Accepted 14 May 1990 